\title{
The Federal Ministerial Bureaucracy, the Legislative Process and Better Regulation
}

\author{
Sabine Kublmann and Sylvia Veit
}

\section{INTRODUCTION}

Since the end of the 1990s, against the backdrop of increasing international competition, growing regulatory density and demands on the output legitimacy of legislative action, there has been a debate around the concept of 'Better Regulation' in Germany and Europe. Better Regulation reforms are directed at anchoring institutional mechanisms to ensure lower costs, enhanced effectiveness and better executability of regulations as well as improving the legislative process. First, these reforms attempt to stem the growing flood of legal norms and overregulation with the objective of the state to enhance its scope of action. Second, they are meant to reduce red tape and the compliance costs of new legislation for businesses,

\footnotetext{
S. Kuhlmann $(\bowtie)$

University of Potsdam, Potsdam, Germany

e-mail: skuhlman@uni-potsdam.de

S. Veit

University of Kassel, Kassel, Germany

e-mail: sveit@uni-kassel.de

(C) The Author(s) 2021

S. Kuhlmann et al. (eds.), Public Administration in Germany, Governance and Public Management, https://doi.org/10.1007/978-3-030-53697-8_20
} 
citizens and public administration. Third, Better Regulation reforms are directed at increasing the effectiveness of political interventions and at systemically considering the non-intended side effects of regulations in order to revise and improve them. While the fundamental debate surrounding reducing red tape, Regulatory Impact Assessment (RIA) and evaluation is by no means new, some facets of the more recent discourse are indeed innovative. This concerns, on the one hand, the influence of the European Union (EU) on national legislation and the bureaucratic burdens caused by adopting EU law. On the other hand, new methods for RIA have been developed, such as the Standard Cost Model (SCM) for estimating bureaucratic costs. Additionally, innovative forms of RIA institutionalisation have evolved, for instance by way of establishing independent advisory bodies by law, such as the National Regulatory Control Council (Nationaler Normenkontrollrat-NKR) in Germany, which brings a new quality to the discourse and practice of Better Regulation. This chapter addresses these developments and specifically outlines the role and functions of the NKR in this context.

\section{Better Regulation as Reform Concept}

Since the second half of the 1990s, Better Regulation ${ }^{1}$ has been established as an international reform wave focussing on the improvement of the production, design, selection and implementation of regulations. The main aim of Better Regulation reforms is to countervail the inherent deficits of regulatory regimes such as the extensive administrative burdens on businesses, a biased inclusion of societal interests or insufficient use of scientific evidence (Lodge and Wegrich 2012). Thus, governments adopt Better Regulation reforms to increase the effectiveness of their regulations and policies but also to strengthen their (democratic) legitimacy (e.g. Radaelli et al. 2013). The concept of Better Regulation is not limited to specific policy areas as it aims 'to improve policy-making and regulation by adopting standards and procedures that govern regulatory decisionmaking across different public policy areas' (Bunea and Ibenskas 2017: 591). ${ }^{2}$ Hence, Better Regulation can be classified as institutional policy (Kuhlmann and Wollmann 2019; Kuhlmann and Wayenberg 2016) or meta-regulation (Radaelli and Meuwese 2009).

Better Regulation is an umbrella term for various tools and instruments to raise the quality of both the process and output of legislation. Typical elements in the 'toolbox' of Better Regulation are Regulatory Impact 
Assessments (RIAs) and its sub-forms, sunset clauses (sunset regulation), consultations, ex post evaluations of policies/laws, approaches to regulatory simplification and tools for risk-based or smart regulation. More recently, digitalisation has influenced this reform area and triggered a debate on the use of electronic forecasting tools and algorithms in policymaking. As RIAs are not only the most widespread tool of Better Regulation but also an instrument with many facets and sub-forms, some further explanations on this instrument are necessary.

RIAs involve a systematic assessment of the impacts of legislative proposals and other policies before they are enacted. RIAs are no new 'invention' of the more recent Better Regulation debate but have a rather long history. In Germany, a list of ten questions to be answered by the lead ministry focussing on the quality and impact of legislative proposals (the so-called Blaue Prüffragen) was established as early as 1984 by the federal government. The practical relevance of this list, however, remained low.

Since the end of the 1990s, increased political efforts to improve policies by systematically integrating RIAs into the legislative process have been observed in many countries. Two core elements of this reform wave can be identified. Firstly, RIAs are explicitly designed as meta-regulation (Radaelli 2010). Hence, the objective is to improve governmental legislative proposals by defining additional 'rules of the game' within the core executive. Secondly, compliance with RIA requirements is regularly supported by the creation of RIA boards or (regulatory) control bodies in charge of quality assurance and control tasks (such as the NKR in Germany). These measures have increased the practical relevance of RIAs and fostered policy learning (Fritsch et al. 2017).

The growing significance of RIAs over the last two decades has been accompanied by a process of functional differentiation, in which various sub-types of RIAs - such as Bureaucracy Cost Assessment with the Standard Cost Model (SCM) or Gender Impact Assessment-have been established in different countries. In addition, different types of 'generic' RIAs exist - the most famous being the Sustainability Impact Assessment (SIA). SIAs focus on a well-balanced appraisal of social, environmental and economic impacts, and on the coupling of sustainability policy (e.g. sustainability indicators) and impact assessment (Russel and Turnpenny 2009). In recent years, ICT development has created new opportunities for analyses and triggered the development and use of electronic RIA tools. The federal government in Germany has introduced an electronic tool as part of the SIA called eNAP (see www.enap.bund.de). 
The OECD has played a crucial role as an important reform promoter in the international diffusion of Better Regulation reforms (DeFrancesco 2012). In Europe, the European Commission has also established itself as a reform promoter by pushing agendas in the field of Better Regulation under different labels. The implementation of Better Regulation measures, as well as the impact of the tools promoted by reform advocates, has become a controversial topic in academic discourse. While some scholars have underlined the potential of these reform tools to improve policies (e.g. Rissi and Sager 2013), others have criticised the reforms for being mainly rhetorical and symbolic with limited impact in practice (e.g. Coglianese 2008). With regard to RIA, empirical studies point to a mainly formal adoption in many countries and considerable implementation deficits and cross-country variation (e.g. Dunlop 2012).

\section{Better Regulation and the Federal Ministerial Bureaucracy}

In Germany, as in most other parliamentary democracies, the coordination and formulation of new regulations and draft laws is one of the main functions of the federal ministerial bureaucracy (see Chaps. 5 and 10). Almost 90 per cent of all federal laws passed by the parliament go back to initiatives of the federal government (Regierungsvorlagen) (Deutscher Bundestag 2019). The remaining ten per cent are mostly initiated by one of the two chambers of federal parliament, the Bundestag or the Bundesrat. There are at least three reasons for this dominant role of the federal bureaucracy in the policymaking process. First, despite the notion of a separation of powers between the legislative and the executive branch, in practice there is no clear dividing line. The head of government (Chancellor) is elected by a majority in the legislature. Majority fractions in parliament and the government are intertwined. Therefore, in many cases, successful legislative initiatives introduced by the Bundestag can actually also be traced back to the executive branch and have been written by ministerial staff. For the most part, strategic considerations or time restrictions are the reason for the decision to formally initiate these laws by the majority fractions in the Bundestag. Secondly, MPs and parliamentary fractions in the Bundestag have far fewer personnel and financial resources at their disposal to develop policy solutions than the government. The government has about 19,000 civil servants working in federal ministries 
and the chancellery (Bundeshaushaltsplan 2019), and more than four times as many civil servants in federal agencies, including governmental research agencies. In addition, a huge number of advisory bodies of the federal government have been established to provide expert policy advice on different topics (see Chap. 5). Finally, the government has substantial financial resources for commissioned research. Compared to the federal government, the parliamentary resources are rather limited: altogether, the Bundestag has about 6000 employees, of whom 3000 belong to the Bundestag administration, about 1150 work for the (currently six) parliamentary fractions (Deutscher Bundestag 2019) and the remaining approximate 1850 are employed as personal staff for the current 709 MPs in the Bundestag. A third reason for the executive dominance in policy formulation lies in the ability to draw on its vast amount of knowledge and policy expertise, which is located in the federal ministries and especially in their basic units (divisions/Referate).

Due to the constitutional principle of minister responsibility (Ministerverantwortlichkeit), federal ministries in Germany are characterised by a strict hierarchy and linear organisation. Each ministry is headed by a single minister. The number of ministers and their policy portfolio is defined by the federal chancellor (there are usually between 14 and 16 ministers). Despite the fact that all legislation and important policy programmes need a cabinet majority (cabinet principle) and, as stated in the federal constitution, the federal chancellor determines and is responsible for general policy guidelines (Richtlinienkompetenz), ministers in Germany have a relatively strong position compared to ministers in many other countries. Every minister conducts his ministry and policy domain independently (departmental principle/Ressortprinzip). Thus, ministers are not subordinate to the head of government and he/she cannot instruct them on how to handle specific issues within their ministries' affairs. In the development of legislative proposals within the executive branch, the strong position of single ministers leads to a dominance of 'negative coordination'. Because of the departmental principle, the lead ministry has considerable autonomy in procedural decisionmaking and consulting interest groups. In policymaking processes, the chancellery exerts influence on the departments by specifying deadlines for consultation. It also has responsibility for releasing departmental legislative proposals (Referentenentwürfe) for interdepartmental coordination and later in the processes leading up to cabinet decision. The chancellery's capacity for fostering policy integration and enforcing its 
own policies is however limited, and even conflict resolution usually takes place among single ministries in the process of interdepartmental coordination (Ressortabstimmung), rather than hierarchically by the chancellery (see Chap. 5). If a conflict cannot be resolved in the Ressortabstimmung, the coalition parties try to negotiate a solution.

The formal policymaking process within the federal government from the first draft of a new regulation to the final cabinet decision is regulated by the Federal Ministries' Joint Rules of Procedure (Gemeinsame Geschäftsordnung-GGO). Besides some of the organisational aspects, the Joint Rules of Procedure stipulate who has to be involved in the lawmaking process and at what point in time. Whenever a new draft law is presented, there is an obligation to consult other federal departments, Länder governments, the local level and interest organisations relevant to that particular policy. The GGO also defines the necessary formal parts of each legislative proposal, notably (a) a summary cover sheet with an overview of the expected impacts in different areas (e.g. compliance costs), (b) the draft law text itself and (c) a detailed explanation of the reasons leading to the respective draft law (explanatory memorandum).

The first attempts at systematising ex ante evaluation of legislation in Germany at federal level date back to the 1970s (Veit 2010). However, it was not before the year 2000 that federal ministries committed themselves to conducting a comprehensive RIA by regulating RIA procedures and competencies in the GGO. It was then, according to the provisions of Section 43 (5) GGO, that the 'consequences of a law' had to be presented in the explanatory memorandum of each legislative proposal. Section 44 (1) GGO further stipulates: 'The consequences of a law are defined as the main impacts of a law: this covers its intended effects and unintended side effects'. The following paragraphs of the GGO list some specific RIA requirements - with an emphasis on cost consequences (e.g. consequences for small- and medium-sized enterprises and implementation costs).

According to the GGO, RIAs have to be conducted by the lead ministry. Since there are no evaluation units within the different federal ministries, RIAs are usually conducted by the same division that has key responsibility for developing the draft law. Before 2006, there was no oversight body within the federal executive with responsibility for evaluating RIA implementation and quality. The Federal Ministry of the Interior was assigned responsibility for supporting the other ministries in their RIA activities, for example by publishing impact assessment guidelines. The quality of RIAs, however, was expected to be discussed by the various 
ministries when coordinating a draft law. Hence, policy coordination and political compromise on the one hand, and neutral analysis of proposed policy impacts based on appropriate methods on the other, were supposed to be realised simultaneously - within the same formal procedures and by the same actors (Veit 2010). To what extent this pattern of institutionalisation changed when the NKR was established in 2006 is elaborated in the following section.

\section{The National Regulatory Control Council}

The National Regulatory Control Council (Nationaler Normenkontrollrat-NKR), which was established on a statutory basis ${ }^{3}$ in Germany in 2006, constitutes a new form of institutionalisation of Better Regulation in organisational, procedural and methodological terms. The NKR is an advisory and control council of ten members that assists the German federal government with Better Regulation and reducing red tape. Its core task is the assessment of all legislative initiatives of the federal government with regard to the presentation of compliance costs and other cost impacts. The aspired political goals and purposes of regulations are thereby not subject to examination according to the NKR law (NKRG). In the following, an overview of the institutionalisation of the NKR as an independent body, its missions and tasks, operating principles and the outcomes of the work of the NKR is given.

\subsection{Institutionalisation of the NKR as an Independent Advisory and Supervisory Body}

The NKR commenced its work in September 2006 after the 'Act on the Establishment of a National Regulatory Control Council' (NKRG) was passed in the previous month. The establishment of the NKR in Germany is to be understood in light of two developments. On the one hand, the federal government drew on the positive response received by the Dutch government's programme 'Bureaucracy Reduction and Better Regulation'. In the Netherlands, where the SCM was developed, an independent expert and advisory body (ACTAL) had already been established in 2000. On the other hand, experience with regulatory impact assessments in Germany had shown that impact assessments were difficult to implement without an assertive authority monitoring their implementation (Veit 2010). One of 
the main arguments for establishing the NKR was, therefore, to set up an independent advisory and supervisory body to systematically monitor and demand that departments assess bureaucracy costs in accordance with their obligations. The NKR is located in the German federal chancellery; however, the NKR is neither supervised by nor subordinate to the federal chancellery or any other authority (Section 1 (1) NKRG). The autonomy and independence of the NKR is also emphasised through its legal anchoring. Contrary to most other advisory bodies of the federal government, disbanding the NKR requires a parliamentary majority.

The NKR consists of ten (eight until 2011) members who work ad honorem. They are nominated by the federal chancellor and appointed by the federal president. In Section 3 (2) NKRG, the profile for members of the council should meet the following requirements: 'The members should have experience in legislative matters within state or social institutions as well as knowledge of economic matters.' The NKR is supported by a professional secretariat with currently 11 employees who are also not subject to any directives issued by the federal chancellery or any department. They are only accountable to the NKR. The secretariat offers civil servants in the departments drafting legislative proposals assistance in implementing the assessments of compliance costs in terms of methodology, while the Federal Statistical Office administers and updates the databank of the assessment exercise. The centrepiece of the formal institutionalisation of the NKR is its obligatory involvement in the inner legislative procedure in the executive. The federal ministries in Germany are obliged to involve the NKR in every regulatory initiative at an early stage. In the phase of interdepartmental coordination, the NKR, thus, has the same rights as other affected departments (Section 45 (1) GGO). The statements of the NKR on legislative proposals-although non-binding for the government - are part of the cabinet draft and are published at the time of introducing the draft to the Federal Parliament (Bundestag) or the Federal Council (Bundesrat) as an appendix to the respective legislative draft (Section 6 (1) NKRG). If there is dissent between the NKR and the government regarding specific issues, the federal government can define this dissenting opinion as the statement of the NKR. The federal government's response is then considered in the further advisory process as an appendix to the legislative draft. 


\subsection{Mission and Mandate}

According to Section 4 (2) NKRG, the main task of the NKR is to assess legislative and regulatory drafts before their presentation to the federal cabinet with regard to compliance with the principles of a standardised assessment of bureaucracy costs and by means of the so-called Standard Cost Model (SCM). ${ }^{4}$ Bureaucracy costs are here to be understood as costs 'incurred by natural or legal persons in fulfilling their duties to provide information. Duties to provide information are obligations deriving from an act, ordinance, bylaw or administrative regulation to procure, make available or transmit data and other information to authorities or third parties' (Section 2 (2) NKRG). Typical examples of information obligations include completing forms and providing statistics, or reporting. In order to calculate bureaucracy costs arising from these obligations, the time and cost expenditure needed to comply with the public information obligations are estimated. Based on a common methodology, the data are multiplied by a tariff, frequency of activity and the number of cases. The result gives information in monetary terms about the bureaucracy costs that entail a legal provision, a legal area or a certain occurrence (e.g. business creation). This procedure can be applied to other target groups (citizens or public administration) in a similar manner. In December 2006, shortly after the establishment of the NKR, the provisions for regulatory impact assessments of the Federal Ministries' Joint Rules of Procedure (GGO) were extended by the obligation to ensure transparency about information obligations and bureaucracy costs for companies, citizens and public administration in the draft proposal and as part of the justification for the law.

In assessing the impacts of Better Regulation policies, critics argue, however, that the bureaucracy reduction measures are not sufficiently perceptible and tangible from the perspective of businesses and citizens. These shortcomings were a crucial reason for extending the NKR mandate in 2011 to foster a more realistic and true-to-life picture of regulatory cost assessments. Initially, the measurement of information obligations for businesses had covered only a minor (and less important) part of the regulatory costs, whereas the weightier and more perceivable part of compliance costs as well as the burdens incurred by citizens and administrations had been ignored. As a result of the extended NKR mandate, the federal ministries not only have to display details of the bureaucracy costs of legislative and regulatory drafts, but also quantify the total compliance costs 
incurred by citizens, businesses and administration at all governmental levels (federal, Länder and local). 'The term compliance costs include the total measurable time expenditure and the costs incurred by citizens, business and public authorities in order to comply with federal legislation' (NKR 2018: p. 11; Section 2 (1) NKRG). In addition to the bureaucracy costs (see above), the measurement of the compliance costs thus includes all direct costs incurred by citizens, businesses and all three levels of public administration (federal, Länder, local levels) by a new federal regulation. Both annual recurrent and one-off burdens-or reliefs-must be presented. The presentation of compliance costs serves two purposes. First, it ensures transparency of the cost implications of a regulatory initiative. Second, it stimulates decision-makers to think about less bureaucratic alternatives and thus minimise compliance costs in general. Without disclosing the compliance costs, a legislative draft cannot proceed to the federal cabinet-it is a binding obligation of the lead ministry that cannot be circumvented.

\subsection{Activities and Results of Regulatory Scrutiny ${ }^{5}$}

Since the establishment of the NKR in September 2006, a total of 4683 regulatory initiatives have been scrutinised, of which 330 regulatory initiatives were allocated to the period from 1 July 2018 to 30 June 2019 (NKR 2019). As mentioned earlier, the amendment to the NKRG in $2011 \mathrm{com}^{-}$ prised a widening of its audit mandate from 'pure bureaucracy costs' (reporting and statistical obligations) to total compliance costs (time and money expenditures that the economy, citizens and administrations at all levels incur by following federal legal provisions) of legislative proposals. Consequently, the scope of the NKR's audit activity and the amount of regulatory initiatives with relevant impacts have increased significantly. Thus, of the 330 proposals examined between July 2018 and June 2019, 127 projects (38 per cent) had a significant impact on one-off and/or annual compliance costs, whereas 203 (62 per cent) incurred only minor or no compliance costs. Compared to the old mandate, which only included the examination of bureaucracy costs, the number of regulatory initiatives with relevant impact in the context of the NKR mandate has virtually tripled. Furthermore, it should be noted that the number of regulatory initiatives with annual burdensome impacts (82 in the reporting period) is much higher than the number of burden reducing regulatory initiatives (26). This can also be explained by the fact that a substantial 
part of the burdensome regulations stems from the implementation of EU directives $^{6}$ and that-for numerous reasons-there is still growth in regulatory activity and a tendency in politics to initiate new legislative projects. This has been confirmed by the increase in annual compliance costs since 2011 (first year of assessment), on balance by a total of $€ 6.6$ billion, of which $€ 4.9$ billion ( 74 per cent of the increase) is allocated to businesses, $€ 1.5$ billion ( 22 per cent) to administration and $€ 221$ million ( 3 per cent) to citizens. Between 2018 and 2019, the annual compliance costs increased on balance by a total of approximately $€ 831$ million (15 per cent; see NKR 2019).

The percentage distribution of the calculated compliance costs among different federal departments indicates where highly regulated intensive policy fields and strong regulatory activity can be found. Here it becomes apparent that the increase in the annual compliance costs can largely be traced back to the regulatory initiatives of the Federal Ministry of Finance with $€ 672$ million. Almost half of the initiatives scrutinised by the NKR in the reporting period were attributed to three ministries (Federal Ministry of Finance: 55, Federal Ministry of Labour and Social Affairs: 47, Federal Ministry of Transport and Digital Infrastructure: 46). On balance, only three federal ministries recorded a substantial annual relief in compliance costs: the Federal Ministry of the Environment with $€ 156$ million, the Federal Ministry of Transport and Digital Infrastructure with $€ 65$ million and the Federal Ministry of Food and Agriculture with $€ 12$ million.

\section{Future Outlook and Lessons for Transfer}

Thanks to the ex ante assessments of compliance costs for each federal legislative regulatory initiative, decision-makers in government and parliament today know with greater accuracy than in the past (and with greater accuracy than in most other European countries), which legislative proposals impose costs on citizens, the economy and the administration. This increased cost transparency has many times resulted in a reduction of bureaucracy $\operatorname{costs}^{7}$ and, following the critical NKR reviews, enabled an improvement in legislative drafts by virtue of reduced compliance costs. In addition, the (hardly quantifiable) positive influence of the NKR's audit activities on the entire legislative process has to be considered. This is especially the case when a potentially critical NKR statement is anticipated by the departments drafting the law and before the proposal can proceed to the federal cabinet. Thus, the NKR activity has contributed to a higher 
institutional sensitivity for the subsequent costs of legislative action today. The NKR has become a widely accepted 'watchdog' and promoter of Better Regulation within the federal legislative process, giving permanent voice to the issues of regulatory burdens and impacts, compliance costs and red tape in Germany. Additionally, it is increasingly taking advantage of its reputation to set the agenda for other fields of administrative reform, such as digital government, modernising public registries and speeding up procedures for large infrastructure projects (see Chap. 19).

A perspective on the future of Better Regulation as a reform doctrine in public administration foresees several developments. First, the federal government could/should focus more sharply on reducing bureaucratic burdens in a more perceptible and everyday life-oriented way, thereby taking a more systematic approach to measuring stakeholders' perceptions. The low perceptibility of cost reliefs is mainly due to the broader notion of compliance costs from the citizens' and businesses' perspective, which involves, inter alia, EU legislation, Länder and local regulations, administrative procedures, customer-business relations, technical standards and so on (IfM-Institut für Mittelstandsforschung Bonn 2019). Thus, the citizens' and businesses' regulatory reality is shaped by a multitude of provisions and rules stemming from various sources and levels, whereas the NKR focuses solely on compliance cost reductions at the federal level. Against this background, there is a trend in Germany towards extending compliance cost measurements beyond the federal level by, for example, establishing regulatory control councils at the Länder level. In BadenWürttemberg and Saxony, for instance, the Länder regulatory control councils are responsible for assessing compliance costs resulting from regulations and administrative directives enacted by the respective Länder governments. In general, the multilevel perspective is a major challenge for regulatory reform policies in federal countries. The separation of the legislative function (predominantly federal level) and the administrative function (predominantly Länder/local levels) makes compliance cost assessments particularly wicked, but all the more important and necessary to ensure better informed, more robust evidence-based policymaking in the multilevel system. However, there is still a lack of well-functioning and generally accepted procedures in Germany that would enable Länder and local governments to be sufficiently involved in federal compliance cost assessments. Further improvement in Better Regulation policies could be achieved by extending the so-called one-in, one-out-rule (OIOO), which was introduced to EU legislation in 2015 on the initiative of the NKR. The 
OIOO rule implies that for new legislative initiatives that incur annual compliance costs to businesses ('in'), a corresponding amount of relief ('out') must be generated by the end of a legislative term at the latestwithin either the draft legislation itself or elsewhere. In the 2018/2019 reporting period, the additional costs to businesses ('in') of $€ 120$ million was outweighed by a relief ('out') of $€ 262$ million, which corresponded to a net relief for businesses of $€ 142$ million. As a result, since its introduction in 2015 , the OIOO balance sheet has shown an 'out' of about $€ 2$ billion net relief for businesses. Nevertheless, this positive OIOO rule does not often tally with reality as perceived by businesses. This is because since 2015 an additional annual 'in' of $€ 435$ million resulting from the implementation of European legislation has been excluded from the OIOO rule. ${ }^{8}$ Consequently, the NKR maintains that this is precisely why European burdens and reliefs must also be covered by the application of the OIOO rule, since it is of complete irrelevance to companies whether costs are incurred as a result of European or national legislation.

Finally, following a joint decision of the federal secretaries of state in 2013, ex post evaluations of legislative acts (in addition to ex ante cost assessments) must be carried out by the departments in a more systematic and methodologically rigorous manner, thus upholding an existing binding decision of the federal secretaries of state responsible for the reduction of bureaucracy. According to this decision, ex post evaluations of impacts and outcomes of new regulations (e.g. regarding political goal attainment, effectiveness, acceptance by stakeholders, unintended effects, etc.) must be conducted for all legislative acts entailing a threshold of (ex ante measured) compliance costs of more than a $€ l$ million per annum. So far, however, the departments have adopted this general rule in a rather reluctant and unsystematic manner, which suggests that further adjustments and a possible standardisation are required. The implementation failure of systematic ex post evaluations of legislative acts illustrates the extreme importance of having not only an independent quality control mechanism for the evaluative process but also an institutionalised, competent and powerful watchdog. The German example shows that Better Regulation as cross-cutting reform measures and meta-regulation needs an advocate within government administration who cannot be circumvented by the departmental policy specialists (Jann and Wegrich 2019) because of its legal foundation and procedural integration in the pre-parliamentarian legislative process. The reduction of bureaucracy costs and-with some restrictions-compliance costs has been working well since the 
establishment of the NKR. However, related topics such as ex post evaluation and sustainability impact assessment (which have both been obligatory in the GGO for some years now), have not been successfully implemented so far due to a lack of organisational institutionalisation and procedural integration.

In order to further promote Better Regulation as an approach to the modernisation of state and administration, it would be desirable if other countries decided to install (independent) bodies for the review of impact assessments too. This applies to members of the European Union in particular, but to other nations as well. To this end, the NKR maintains a close liaison with six other independent bodies in Europe tasked by their government or their parliament with reviewing impact assessments and together with the NKR have formed the network 'RegWatchEurope'. Besides the German NKR, the network consists of the Adviescollege Toetsing Regeldruk (ATR) from the Netherlands, the Regulatory Policy Committee (RPC) from the United Kingdom, the Swedish Regelradet (SBRC) and the Norwegian Regelradet (NBRC) as well as the Regulatory Impact Assessment Board (RIAB) from the Czech Republic and the Finnish Council of Regulatory Impact Analysis (FCRIA). The purpose of the network is to enable the exchange of experience and knowledge among its members and the representation of common interests at the EU level, specifically vis-à-pis the Regulatory Scrutiny Board (RSB) of the EU Commission and, in an international context, the Regulatory Policy Committee of the OECD. These multilateral, European-scale and international exchanges offer the opportunity to share different national experiences in impact assessments with representatives from other OECD member states and thus promote the model of independent regulatory scrutiny on a European scale and in the international context.

\section{Notes}

1. In practice, Better Regulation reforms are known by different names. Common labels include smart regulation (often used by the European Commission), high-quality regulation and regulatory reform.

2. As efforts in the area of Better Regulation often include the (increasing) use of scientific evidence and expertise to improve policy decisions and regulations, the concept is closely related to another reform concept: evidencebased policymaking (EBPM). At the core of EBPM lies the idea of a 'rationalisation' of political decision-making by systematically integrating 
scientific evidence and expertise in policymaking processes and by strengthening 'positive coordination' within the politico-administrative system.

3. Gesetz zur Einsetzung eines Nationalen Normenkontrollrates vom 14.8.2006 (Act on the Establishment of a National Regulatory Control Council-NKRG).

4. The assessment of bureaucracy costs by means of the SCM was developed in the 1990s in the Netherlands. Subsequently, this instrument spread across Europe.

5. The following summary of essential fields of activity and audit results of the NKR refers to the reporting period from I July 2018 to 30 June 2019 (NKR 2019).

6. A considerable proportion of the legal provisions prevailing in Germany and approximately half of the compliance costs in the reporting period stem from EU law. However, up to now, only EU directives that are to be transposed into national legislation (not EU regulations) that constitutes immediately applicable law in Germany are systematically recorded by the NKR audit in which a 'transparency gap' can be detected.

7. The 'pure' bureaucracy costs, which by definition exclusively comprise information and statistical obligations for the economy, were reduced between 2006 and 2011 by 22.3 per cent NKR $(2013$, p. 28).

8. This exception was carved out by a joint decision of the federal administrative state secretaries in January 2016.

\section{REFERENCES}

Bunea, A., \& Ibenskas, R. (2017). Unveiling Patterns of Contestation Over Better Regulation Reforms in the European Union. Public Administration, 95, 589-604.

Coglianese, C. (2008). The Rhetoric and Reality of Regulatory Reform. Yale Journal of Regulation, 25, 85-95.

DeFrancesco, F. (2012). Diffusion of Regulatory Impact Analysis Among OECD and EU member states. Comparative Political Studies, 45, 1277-1305.

Deutscher Bundestag. (2019). Statistik der Gesetzgebung-19. Wahlperiode, Stand, 23(8), 2019.

Dunlop, C. A. (2012). The Many Uses of Regulatory Impact Assessment: A MetaAnalysis of EU and UK Cases. Regulation \& Governance, 6(1), 23-45.

Fritsch, O., Kamkhaji, J. C., \& Radaelli, C. M. (2017). Explaining the Content of Impact Assessment in the United Kingdom: Learning Across Time, Sector, and Departments. Regulation and Governance, 11, 325-342.

IfM-Institut für Mittelstandsforschung Bonn. (2019). Bürokratiewahrnehmung von Unternehmen. IfM-Materialien Nr. 274. Bonn. 
Jann, W., \& Wegrich, K. (2019). Generalists and specialists in executive politics: Why ambitious meta-policies so often fail. Public Administration, $97(4), 845-860$.

Kuhlmann, S., \& Wayenberg, E. (2016). Institutional Impact Assessment in Multi-Level-Systems: Conceptualizing Decentralization Effects from a Comparative Perspective. International Review of Administrative Sciences, 82(2), 233-254. https://doi.org/10.1177/0020852315583194.

Kuhlmann, S., \& Wollmann, H. (2019). Introduction to Comparative Public Administration: Administrative Systems and Reforms in Europe (2nd ed.). Cheltenham: Elgar.

Lodge, M., \& Wegrich, K. (2012). Managing Regulation: Regulatory Analysis, Politics and Policy. Basingstoke: Palgrave Macmillan.

NKR. (2013). Transparency of Costs Improved, Focus on further Burden Reduction. Annual Report 2013 of the Nationaler Normenkontrollrat, Berlin.

NKR. (2018). Germany: Less Bureaucracy, More Digital Services, Better Regulation. Let's get to it! Annual Report 2018 of the Nationaler Normenkontrollrat, Berlin.

NKR. (2019). Content First, Legal Text Second. Designing Effective and Practicable Legislation. Report of the Nationaler Normenkontrollrat, Berlin.

Radaelli, C. M. (2010). Regulating Rule-Making via Impact Assessment. Governance, 23(1), 89-108.

Radaelli, C. M., \& Meuwese, A. (2009). Better Regulation in Europe: Between Management and Regulation. Public Administration, 87(3), 639-654.

Radaelli, C. M., Dunlop, C. A., \& Fritsch, O. (2013). Narrating Impact Assessment in the European Union. European Political Science, 12, 500-521.

Rissi, C., \& Sager, F. (2013). Types of Knowledge Utilization of Regulatory Impact Assessments: Evidence from Swiss Policymaking. Regulation \& Governance, 7, 348-364.

Russel, D., \& Turnpenny, J. (2009). The Politics of Sustainable Development in UK Government: What Role for Integrated Policy Appraisals? Environment and Planning C: Government and Policy, 27(2), 340-354.

Veit, S. (2010). Bessere Gesetze durch Folgenabschätzung? Deutschland und Schweden im Vergleich. Wiesbaden: VS Verlag. 
Open Access This chapter is licensed under the terms of the Creative Commons Attribution 4.0 International License (http://creativecommons.org/licenses/ by $/ 4.0 /$ ), which permits use, sharing, adaptation, distribution and reproduction in any medium or format, as long as you give appropriate credit to the original author(s) and the source, provide a link to the Creative Commons licence and indicate if changes were made.

The images or other third party material in this chapter are included in the chapter's Creative Commons licence, unless indicated otherwise in a credit line to the material. If material is not included in the chapter's Creative Commons licence and your intended use is not permitted by statutory regulation or exceeds the permitted use, you will need to obtain permission directly from the copyright holder. 